\title{
The Amateur Astronomer
}

\section{By JOHN HODGES, Regina Astronomical Society}

It may be easy to give a general definition of an amateur, but I believe it is more difficult to define an amateur astronomer. Amateur astronomers run the entire gamut from those with equipment equal to that of professional astronomers, to those, like you and me, who have to rely principally on eyesight. Some amateurs become highly excited over each new phenomenon observed and seek elaborate explanations of it; while others just sit back and enjoy the show for what it is. Most of us fall into the latter category.

"How does one start?" is the plea of those people beginning to take an interest in astronomy. This question is difficult to answer without knowing which branch of astronomy interests you most. One thing we all have in common, however-we want to have enjoyment without equipment that is expensive and difficult to operate.

If I were asked to conduct a class in astronomy, I would make the following suggestions. Find a place away from city lights and traffic and with a gentle north slope. Lay down a ground-sheet, or piece of canvas, or heavy brown paper, to form a fairly waterproof insulation between you and the ground. On top, put a folded blanket for padding the hard ground. Next comes you, and on top another blanket to keep you warm. From this vantage point you can see Polaris (North Star) and learn some constellations in relation to it.

You already have an armful of equipment-two blankets and a ground sheet, but this is necessary if you are going to be com'fortable and to remain comfortable for a period of time. Two more pieces of equipment will complete your geara flashlight and a star map. The flashlight could have its lens covered with red cellophane so that you will not lose your night vision with it turned on.

The star charts present a problem. A set consists of four charts, one for each quarter of the year. You use the one appropriate to the time of the year, and hold it so that the Big Dipper (Ursa Major) is located on the chart in the same position as in the sky you are watching. Then you pick cut the other constellations with relation to the Pole Star (Polaris).

There is a good, but inexpensive, book on "Stars" in the Golden Book series, available at the Canada Book and Drug Store in Regina, and the Regina Astronomical Society has charts which the president, Mr. M. Worel, will send out to you to use with it. Since the charts should be kept flat in mailing or packed in a mailing tube, twenty-five cents should be sent with your request, to ccver the cost of mailing.

Why the emphasis on locating constellations? To answer this question, let us suppose that a comet is report$\epsilon d$ as making its appearance in the constellation of Pisces just as the sun sets on April 21. A little study of the chart would show where Pisces would be at sunset. You now have a pcint of reference for locating objects. It is easier to get around in the sky than in the average town, and there is no traffic problem!

If you own binoculars, of any size or power at all, so much the better. Once you have located a constellation and learned its boundaries, look at it closely with binoculars. You will recognize any planet in the area because planets enlarge with binoculars and stars do not. I must warn you that binoculars need fine focussing for looking at the stars.

If you are interested in astronomy, you can help me in preparing this column for the BLUE JAY. Tell me what you like to read about. A few letters with questions would help immensely. In my answers, I shall try especially to be helpful to the beginner. After all, I am an amateur too and I should like you to get as much enjoyment from this study as I do. 